\title{
Cultura nordestina, sociedade carioca (Representações de migrantes nordestinos na chanchada, 1952-1961)
}

\author{
JÚLIo CÉSAR LoBo*
}

\begin{abstract}
Resumo: Este ensaio visa localizar, descrever e interpretar aspectos de representação de uma suposta identidade regional nordestina no cinema brasileiro de ficção entre os anos de 1952 e 1961. Além disso, buscamos fazer um breve levantamento de algumas das matrizes dessas representaçães e as suas motivações para tanto. Com esse propósito, buscamos analisar quais os traços allturais que as narrativas da amostra consideram como exclusivos daqueles que nasceram ou se formaram no Nordeste do Brasil; verificar e disautir se, nessa amostra de rẹpresentações, há dados que possibilitem uma caracterização dos nordestinos por naturalidade, e se seria a auto-atribuição um fator relevante para o processo de constnução de uma identidade nordestina no nosso cinema.
\end{abstract}

Palavras-chave: nordestinos; chanchada carioca; história e crítica; cinema brasileiro; séarlo 20.

\section{Introdução}

A nossa tarefa neste texto é analisar as representações de migrantes nordestinos em um conjunto de filmes de longa-metragem de ficção, no subgênero chanchada, realizados no Rio de Janeiro entre os anos de 1952 e 1961. Naquele período, essas obras tiveram uma maior regularidade de produção e uma maior aceitação popular. O nosso recorte teve como critério principal a presença de uma personagem identificada como nordestina e migrante no papel principal ou em papel secundário.

Enfatizamos os migrantes, uma vez que, com eles, temos elementos que tornam pertinente o aporte de conceitos e métodos do estudo da assimilação de migrantes no meio urbano (Germani, 1974, p.141-65), estudo esse interes-

Doutor em Ciências da Comunicação (Universidade de São Paulo). Professor-orientador do Programa Multidisciplinar em Estudos de Pós-graduação em Cultura e Sociedade da Universidade Federal da Bahia e do Mestrado em Educação e Contemporaneidade da Universidade do Estado da Bahia. sado nas seguintes indagações: quais as origens dos migrantes? Quais as motivações deles para a migração? Como se dá a participação do migrante na metrópole? Há ocorrência ou não da assimilação? Quais as características dos migrantes antes da migração? Quais as condições objetivas ou ambientais que se apresentavam para eles até então? Tende-se a considerar como majoritária a presença de migrantes de origem rural nas metrópoles brasileiras, uma vez que características de modernização tenderiam a constituir fortes fatores atrativos para as migrações.

As mudanças características do processo de modernização ocorrem em quatro níveis, mas, para nossos propósitos, trataremos apenas de dois deles, a saber:

$\square$ no nível social, ocorre o desenvolvimento urbano e a intensa migração do campo para a cidade, entre outros aspectos;

$\square$ no plano cultural, expandem-se os meios de comunicação de massa e a educação 
secular, retirando da família parte de suas tarefas de socialização do indivíduo e contribuindo para o desenvolvimento de uma nova escala de valores, que rompe com a estrutura da família tradicional (de caráter patriarcal).

Simultaneamente, através da análise de estereótipos, tentamos levantar os traços que nos interessam para os objetivos propostos.

Nunca é demais frisar que a estereotipação é um processo. Em geral, ele assim ocorre: há a produção de uma matriz, que pode provir da série literária, da ensaística, do folclore e da música popular, entre outras fontes. Um segundo passo em um processo de estereotipação é a duplicação, em que o traço destacado, freqüentemente deslocado do contexto que o gerou, começa a ser produzido em série. Tem-se ainda a simplificação, em que as nuances de uma caracterização são como que apagadas para facilitar o consumo rápido de um pré-conceito. Ao final desse processo, tem-se a generalização, tipo "é tudo a mesma coisa".

Por que se estudar representações de uma identidade social regional através da análise de estereótipos? Essa indagação talvez fosse mais funcional para o nosso uso aqui se reformulada assim: para que servem os estereótipos?: a) o estereótipo comporta uma conjunto de imagens de segunda mão (Lippmann, 1973) que mediatizam nossa relação com o real através do que a nossa cultura definiu previamente. Essas imagens compõem figurações invariáveis, artificiais e superficiais, que se repetem automaticamente ao infinito (Starfield, 1993, apud Amâncio, 2001, p. 32); b) os estereótipos fornecem também ao indivíduo uma espécie de ajuda psicológica para uma rápida apreciação de situações (e rápida justificativa), como já apontara Lippmann, em 1922, porque, sendo eles estruturações prontas, sinalizam como certas situações devem ser padronizadas pelos indivíduos em uma situação identificada especificamente ou não. O estereótipo é acionado ao se denominar automaticamente um objeto através de um conjunto de atributos.

No entanto, no corpus trabalhado, raras são as personagens devidamente identificadas pela origem rural para que a cultura "urbana" pudesse surgir como diferença. Ainda com relação à origem dos migrantes, a naturalidade talvez seja o atributo mais utilizado na caracterização mais rápida de uma personagem com relação à sua identidade social regional, a despeito de esse atributo, em nosso entendimento, parecer ser o mais frágil de todos. Entre outras desvantagens, esse atributo tende a naturalizar o social, como na comédia Sai dessa recruta! (RJ, 1961), em que Mário Tupinambá interpreta um cabo do Exército a serviço no Rio de Janeiro. Para ele, o simples fato de ter nascido na Bahia já seria o suficiente para que fosse dotado, bem como seus conterrâneos, de uma série de virtudes, proclamadas com ênfase, a saber: "Baiano não sobe em coqueiro errado" e "Um baiano não tem medo, o que um baiano tem é prudência".

É claro que uma comédia trabalha com tipos, estereótipos e clichês verbais, mas o curioso, no primeiro filme citado, é que as únicas identidades regionais identificadas são as de dois baianos, como se as identidades regionais das outras personagens principais ou coadjuvantes, militares do Exército e residentes de uma pensão próxima ao quartel no Rio de Janeiro, não fossem relevantes.

O enfoque da questão da origem, associada à identidade regional, através da auto-atribuição, talvez seja o de maior riqueza instrumental nessa análise, uma vez que diz respeito às identidades negociadas, comuns na contemporaneidade. $\mathrm{Ou}$ seja, a questão da auto-atribuição traz à tona, entre outras coisas, o fato de que uma identidade que um grupo "de fora" etiqueta em uma pessoa ou em um grupo social pode não ser a identidade pretendida por ele ou pelo grupo por vários motivos. Para a personagem interpretada por Tupinambá, no último filme citado, uma certa baianidade é a sua essencialidade, baianidade esta que é duramente rejeitada, em Quem roubou meu samba? (RJ, 1958), pela enfermeira Iolanda (Nancy Wanderley), a eterna noiva (doze anos de noivado) do empresário Leovigildo Coruja "diretor-proprietário" da agência de investigações A Eterna Vigilância -, interpretado por Ankito. Ele se diz o representante de um compositor do morro que vende um mesmo samba para duas gravadoras. Um terceiro interessado seqüestra o citado sambista. A participação de 
Iolanda acentua-se quando ela se envolve em uma briga com seqüestradores do compositor, que havia sido retirado do hospital onde ela trabalha, saindo-se bem na empreitada. Ao ser elogiada em sua performance pugilística por um dos seus colegas com um "êta, baiana!", ela prontamente the responde: "Baiana, vírgula. Eu sou é pernambucana".

Da mesma forma que em $O$ camelô $d a$ Rua Larga, Nancy Wanderley representa, em Quem roubou meu samba?, a migrante pernambucana cujos valores positivos dificilmente conseguem influenciar os seus eternos noivos picaretas, como se traduz dessa fala dela para Leovigildo: "E aí, arranjou emprego? Ô, xente! Dou um duro danado da moléstia... e ele fica vagabundeando. Se você quer ganhar sem fazer nada, arranje uma vaga de jacaré no jardim zoológico". O tipo interpretado por Ankito ${ }^{1}$ se inseria em uma ampla galeria de que se alimentava a chanchada, que, segundo Sérgio Augusto (1989), apenas abrasileirava um repertório italiano:

Pobretões que se fingem de ricaços, gêmeos que se engalfinham por uma herança, mulheres que simulam adultério para despertar a atenção de maridos relapsos e prevaricadores, motoristas de praça e modestos comerciantes, enredados em intrigas policiais, humildes funcionários públicos iludidos pela 'sorte grande', compositores ludibriados por vigaristas teatrais e radiofônicos. (1989, p.69)

Um outro procedimento de estereotipação, ainda no tópico origem dos migrantes, é a associação de alguns de seus traços fisiognômicos a uma naturalidade com tons discriminatórios. No Brasil, isso se dá freqüentemente com relação a nortistas ou nordestinos, fato que repercute nas artes também. Em Virou bagunça (RJ, 1960), o Trio Jerimum (Trio Irakitan) é despachado sumariamente de uma oportunidade de participar de um show em uma TV carioca sob o argumento de um de seus diretores de que ele não queria um "cabeça-chata" na tela de sua emissora porque o "povo" iria pensar

1. O tipo do empresário desonesto, que sobrevive ludibriando sambistas de morro, encontra-se representado, na época áurea das chanchadas, também em dramas como Rio, Zona Norte (RJ, 1957), no caso, interpretado por Jece Valadão. que os seus televisores estavam com defeito. Essas discriminações em torno do "cabeçachata" são a popularização também de uma prática tida como científica, que era o discurso socioantropológico ancorado em uma biotipologia.

A estigmatização e a correspondente associação de um traço fisiognômico aos naturais de um determinado estado brasileiro têm uma matriz literária bem pontual no romance $O$ sertanejo, de José de Alencar (1978 [1875]), precisamente nesse trecho: "O sobrinho do capitão-mor [...] era mancebo de trinta anos, de baixa estatura, mas robusto, com ombros largos e cabeça-chata, tipo mais comum do sertanejo cearense e que o distingue de seus vizinhos limítrofes" (p. 222). Para que esse discurso migrasse para a cultura popular foi um pulo, como se comprova nesses versos: "Ôreia de abana fogo/ Cabeça de bate-sola/ pestana de porco ruivo/ queixada de graviola/ canela de maçarico/ pé de macaco de Angola" (Navarro, 1998, p. 52)

Ainda com relação a características dos migrantes em suas origens, tende-se a considerar a investigação sobre a motivação como um aspecto fundamental em estudos migratórios. Esses motivos variam, podendo ser da seguinte natureza: de bases econômicas (salários baixos ou desocupação etc.); domésticas (desejo de se reunir a um ou a mais membros da família), e educacionais. Esse último item é raríssimo no cinema de ficção. Há ainda outras motivações, relacionadas ao desejo de novas experiências, de escapar do ambiente tradicional, de mobilidade e aspirações maiores etc., mas que não se apresentam com freqüência significativa em nosso corpus.

Em síntese, poucos são os filmes de ficção trabalhados em nosso corpus que têm algum cuidado em fornecer dados a respeito das motivações para as migrações em direção ao Sudeste do País. Quando isso acontece, a motivação é generalizante: busca de melhores condições de vida. Quanto à decisão de migrar, são privilegiados os indicadores relativos aos fatores de expulsão, principalmente no campo, e fatores de atração. Sabe-se que, em regiões tidas como desenvolvidas, a migração para lá está relacionada principalmente com o aumento da demanda 
de trabalho, criado pelo crescimento industrial (Germani, 1974, p. 142). No entanto, nos filmes do ciclo da chanchada carioca, a indústria cultural (restrita ao rádio e às gravadoras) e o palco do teatro de revista ou de uma boate na Zona Sul são os principais fatores atrativos para migrantes nordestinos, vistos quase sempre já alojados na metrópole. Alguns filmes chegam até a ter discretos sambas-exaltação ao Rio de Janeiro que funcionam, no universo da indústria cultural, como uma espécie de fator atrativo, a exemplo dos registrados em Rio fantasia (RJ, 1957) e em Virou bagunça.

No primeiro dos filmes citados, enquanto a migrante nordestina Elisa (interpretada pela fluminense Eliana) acaba de se alojar na pensão, sonhando com um determinado futuro (colchão de molas, telefone, retrato no jornal e banheiro no quarto), ouvem-se em off os versos de "Assim é o meu Rio" (I. Oliveira - J. Araújo) celebrando alguns fatores atrativos da ex-Cidade Maravilhosa, a saber: "Vem ver a morena queimada/ Na areia deitada/ Vem ver edifícios subindo/Lá longe sumindo/ rasgando o espaço/ a imagem de Cristo/ braços abertos a simbolizar/ De janeiro a janeiro/ Esse Rio.../ Esse povo que, cedo/ levanta para ir trabalhar". ${ }^{2}$ Em Virou bagunça, a louvação serve como fundo musical para os créditos de abertura: "Eu vim morar no Rio/ No Rio, eu vim ficar. Foi só chegar, olhar, descer, vencer/ e ao Rio amar. Eu vim vencer no Rio/ Eu vim me endinheirar/ Eu vim ganhar milhões, bilhões, trilhões/ Eu vim me arrumar".

Um outro aspecto que se deve levar em conta nas condições objetivas para a migração está nas circunstâncias da translação (Germani, 1974, p. 161-2), as quais dizem respeito aos canais pelo quais ocorre a translação e que podem estar relacionados com o trabalho, com parentes e amigos. Esses últimos têm-se caracterizado nas migrações em cadeia: os pioneiros, já estabelecidos razoavelmente, servem como um estímulo para os que quedaram na origem regional comum. Esses pioneiros são fundamentais na ajuda para uma ocupação e como

2. Com relação a essa última imagem positiva dos cariocas, Vinicius de Moraes (1992) pensava ao contrário, pelo menos é o que aparece como epígrafe de seu Roteiro lírico sentimental da cidade do Rio de Janeiro: "O carioca é um sujeito que, por princípio, acorda tarde e chateado" (p. 7) uma espécie de "tradutor" dos códigos das metrópoles para aqueles que vêm de regiões de outro perfil socioeconômico e cultural. Esse aspecto, de fundamental importância, na realidade imediata, para a migração de mulheres até algum tempo, somente pode ser notado em Virou bagunça, pois o trio vem ao Rio, seguindo a trilha de um tio bem-sucedido. Ao chegar à excapital federal, o trio descobre que o tio de um deles já morreu há anos, deixando-lhe como herança um sobrado em ruínas.

\section{Normas, crenças e valores de origem}

O estudo do nível normativo das migrações pressupõe uma atenção a normas, crenças e valores da sociedade de origem (Germani, 1974), itens que podem vir a traduzir não somente os critérios que pesarão na avaliação dos fatores expulsivos e atrativos, brevemente expostos acima, bem como regulam as migrações. Essas últimas compõem as condições objetivas: oportunidades de emprego, moradia, salários, educacionais e similares. $O$ fato é que normas, valores e pautas comportamentais são traços culturais relevantes quando se busca caracterizar uma dada identidade social. Nesse aspecto, uma outra construção cinematográfica muito freqüente a propósito de nordestinos ou nortistas, tão forte quanto a de um místico nato, é a de uma elogiada valentia, de uma singular macheza, que se anuncia por trás da expressão "cabra macho", que, naturalmente, surgiu em um contexto de valoração positiva, mas que retorna, via processo de estereotipação, com uma carga negativada.

Uma certa leitura dessa estereotipação pode acentuar uma recusa a um racionalismo ou a uma postura conciliatória, no mínimo, por parte de determinados brasileiros que nasceram em determinada região do país. Albuquerque Jr. (2005, p. 32-36), ao analisar o estereótipo do machão nordestino, chama a nossa atenção para esses aspectos: a influência de Euclides da Cunha na difusão de atributos relacionados a coragem, destemor, valentia e virilidade; a associação desse "último dos machos" com as representações mais corriqueiras do coronel, do jagunço e do cangaceiro, e a perigosa associação "ser nordestino é ser macho" (p. 32-36). 
Ao final do seu ensaio, intitulado "Cabra da peste!”, esse historiador nordestino adverte:

\begin{abstract}
Alimentar o mito do 'cabra macho' é contribuir para a permanência, inclusive, da violência contra as mulheres e, ao mesmo tempo, alimentar um modelo de masculinidade, que tenta manter um tipo de relação entre homens e mulheres que viria desde o período colonial e que, por isso mesmo, é vista como natural, como eterna. Este modelo vitima os próprios homens, já que os coloca em constantes situações de risco e deles exige renúncias afetivas e emocionais importantes, como a do exercício da paternidade e da expressão de sentimentos e emoções. (p.
\end{abstract} 36)

Curiosamente, a representação de valentia como um traço cultural de nortistas ou nordestinos migrantes vai-se fixar nas chanchadas através de personagens femininas, interpretadas principalmente pela cearense Nancy Wanderley - sempre em papel de "pernambucana". Para o que se quer discutir aqui, os filmes com Nancy que se mostram mais produtivos são aqueles em que ela contracena com baianos, principalmente com Zé Trindade.

Nancy é a costureira em uma boate e a eterna noiva do camelô do título (Zé Trindade) em $O$ camelô da Rua Larga (RJ, 1958). Após uma confusão nos bastidores daquele local, a personagem-título troca a sua mala de muamba por uma outra idêntica, contendo dinheiro falso. Ignorando o fato, ele não se aproveita da súbita fortuna, que é descoberta pela dona da pensão em que reside. $\mathrm{O}$ camelô-protagonista vive a fugir do "rapa", dos marginais, a quem pertence a mala venal, e do assédio da sua eterna noiva. No momento em que os marginais buscam recuperar sua mala, trava-se uma briga nos bastidores, e o camelô arremeda um discurso de valentia, enunciando-a juntamente com sua naturalidade: "Num baiano decidido, ninguém bota a mão: vai tudo virar mungunzá". O que se segue é o citado camelô fugindo à luta. Enquanto ele arrota valentia, ela, discreta, é quem é valente e bastante dura com ele, aplicando-lhe safanões quando ele tenta assediar sexualmente as coristas da boate. Tem-se, então, no caso desse filme, um ato curioso: a auto-identificação não vem associada a uma auto-estereotipação positiva, mas, sim, com uma inversão, que aponta para uma covardia. É claro que a composição da personagem-título ${ }^{3}$ não comporta apenas covardia, uma vez que, para trabalhar, ele precisa desafiar a lei, o que demanda algumas virtudes, como aponta Chaia (1980): "Só o desejo de trabalhar, no caso, vender seus trambiques, não basta; ele deve ser manhoso, esperto ou ladino para driblar os homens da lei" (p. 63).

Em No mundo da lua (RJ, 1958), Nancy faz parte de uma quadrilha que põe um agricultor potiguar no lugar de um sósia seu, o proprietário de uma fábrica de cimento, papel duplo desempenhado pelo gaúcho Walter D'Ávila (19141996). O agricultor está vindo ao Rio de Janeiro em busca de uma mulher que conhece apenas por correspondência, sendo acompanhado na viagem por um sanfoneiro potiguar, interpretado pelo fluminense (de Nova Friburgo) Reginaldo Farias. A função de Nancy é estratégica no bando, mas as suas falas buscam realçar uma propensão à grossura e a uma proposta de truculência física, como se tem nesses trechos: "Guarde essa valentia aí, ô palhaço!" (para um comparsa) "e não grita comigo, não, ô, careca, se não vai acabar conhecendo o gostinho do chumbo quente" (para o violento chefe). Em um outro momento da narrativa, ela defende a tortura do seqüestrado. Nesse filme, como em muitos outros, Nancy é a vilã e caracterizada como pernambucana, mas, em nenhum dos outros, ela aparece como seqüestradora e torturadora.

Em O batedor de carteiras (RJ, 1960), a cearense Nancy Wanderley é novamente uma pernambucana, que vem ao Rio de Janeiro tentar a vida como doméstica. A necessidade de deixar claro desde o início a sua pernambucanidade fica evidente logo que ela salta do trem na Central do Brasil e é saudada por um "Salve a Bahia!", de Mão Leve (Zé Trindade), personagem-título: "Sou pernambucana, visse? E meu nome é Honorina". Imediatamente, Mão Leve se identifica como mineiro. Essa identificação serve tão-somente para estimular no espectador, especialmente aquele de 1958, as associações

3. De passagem: nem era nordestino o primeiro camelô do Rio de Janeiro real. Tratava-se do americano Whitemore, que vendia um elixir contra o mau hálito na Rua do Ouvidor, a partir de 1853 (Castro, 2003, p. 152). 
com figuras dos mineiros no poder, como Juscelino Kubitschek, presidente da República, Negrão de Lima e o responsável pela construção de Brasília, Israel Pinheiro. Diferentemente do filme anteriormente citado, $O$ batedor de carteiras tem um final regenerador: Mão Leve resolve deixar de ser um meliante, promete procurar um emprego e se casa com a doméstica pernambucana.

A última e talvez mais acentuada caracterização da cearense Nancy Wanderley como a copeira "pernambucana" é em Samba em Brasília (RJ, 1960). O dado novo aqui é que a sua naturalidade não é anunciada, mas, sim, subentendida pelos referenciais culturais que ela distribui e que são tidos como relativos ao que se entende por "cultura pernambucana", como "Eu não disse que essa bichinha era praticante de catimbó". A "bichinha" é a fluminense Eliana Macedo, interpretando Terezinha, uma cozinheira baiana. Durante toda a narrativa, a postura da copeira pode ser tomada como fortemente antipática e acaba servindo como uma "escada" para o brilho de Terezinha, talvez a representação mais completa da internalização dos valores da sociedade recipiente de todas as chanchadas deste corpus.

O brilho, a que nos referimos acima, pode ser melhor nuançado no sucesso com que enfrenta diversas contendas de natureza identitária: a) no morro onde mora, ela disputa o posto de porta-bandeira de uma escola de samba com uma carioca, que a discrimina racialmente ("essa branquinha... também é a primeira vez que eu vejo uma branca assim metida a porta-bandeira..."), e ganha a parada sem praticar a exclusão; b) na cozinha dos grã-finos, em que vai substituir temporariamente uma tia, ela enfrenta outra disputa, aquela já citada com a copeira, mas, aqui, o conflito é de natureza intra-regional com ranços étnico-religiosos, pois a pernambucana subestima as realçadas, no filme, virtudes de uma culinária afro-baiana, além de se referir pejorativamente ao candomblé, e c) finalmente, para variar, ela fragiliza a identidade de classe burguesa ao seduzir e namorar o filho dos patrões. Como se tudo isso ainda fosse pouco, cabe a essa cozinheira baiana e favelada, em longa e bela seqüência, cantar uma utópica Brasília.
Em Mulheres à vista (RJ, 1959), Zé Trindade é João Flores, um malandro que tenta seduzir uma viúva rica (Estelita Bell), tendo como objetivo escuso que ela patrocine o show de um grupo de artistas, abandonados por um empresário desonesto (o eterno vilão Renato Restier). As expressões relativas à naturalidade da personagem e de quem a interpreta (Zé Trindade) são - como acontece na maioria dos filmes estrelados por ele - veiculadas gratuitamente. Assim, o dado da identidade regional não surge como contrafação a uma alteridade, mas, sim, como o sinal mais visível de uma distinção, como se a naturalidade pura e simplesmente constituísse fonte de prestígio, como se tem nessas falas dele: "Quem nasce na Bahia escorrega, mas não cai" e "Baiano burro nasce morto".

Em Marido de mulher boa (RJ, 1960), Zé Trindade é o sócio de Otelo Zeloni em uma casa de modas e casado com a ex-mulher deste, interpretada por Renata Fronzi. Ancorado em um bordão machista - "Sou casado, mas não sou fanático" -, o protagonista vive a assediar sexualmente clientes e jovens modelos dessa loja. Como acontece nos filmes em que Zé Trindade é co-argumentista ou autor de diálogos adicionais, abunda a auto-identificação de finalidades duvidosas, tais como nas frases "Vai começar o baianicídio", "Perdoa o seu baiano, velho de guerra" (dirigindo-se à esposa) e nessa pilhéria: "É a primeira vez que um baiano é apanhado em flagrante, pela própria mulher, com a própria mulher. Quando a Bahia souber disso, vai ser um vatapá para conferir". É claro que uma comédia trabalha com tipos e corrosões, mas, se a identificação regional parece ser um dado importante para a produção do riso de escárnio, estranha-se que não haja qualquer referência ou auto-referência à origem italiana de Zeloni nem à origem argentina de Fronzi nem aos carregados sotaques de ambos.

Um dado importante a mais nas observações sobre os filmes Mulheres à vista e Marido de mulher boa talvez esteja no fato de que esse movimento de distinção pela naturalidade acionado obsessivamente pelas personagens de Zé Trindade pode voltar com sinal trocado, agora associando-se defeitos e traços negativos de "paraíbas" e "baianos" à simples naturalidade 
de suas personagens principais. Por sinal, a composição das personagens desse ator baiano em todas as chanchadas de que participou é curiosa: enquanto ele tem uma preocupação em anunciar sua naturalidade (verdadeira), o seu comportamento tende a ser associado ao que se tem como traços de representação estereotipada de uma outra identidade regional, a carioca, que é a do malandro, uma construção que, por si só, já demandaria um outro ensaio. Essa peculiaridade já foi assim apontada por Vieira (1990): “Já o coroa, na pele de Zé Trindade, era a própria imagem do cafajeste moderno, esperto, cheio de sabedoria popular" (p. 174-5).

Notamos atrás que a representação da valentia como traço cultural de nortista ou nordestino na chanchada aparece freqüentemente associada à mulher. Talvez essa estereotipação tenha uma matriz bem clara: a canção "Paraíba" (L. Gonzaga - H. Teixeira), principalmente nesses versos: "Paraíba, masculina/ Muié-macho, sim sinhô!". Vamos trazer aqui um pouco da memória da sua construção para termos uma idéia dessa súbita masculinização (estereotipação) da mulher natural da Paraíba. A canção fora encomendada pela Casa Civil do presidente Eurico G. Dutra para promover a candidatura de José Américo de Almeida, o autor de $A$ bagaceira, a governador da Paraíba em 1950. O refrão buscava enfatizar o posicionamento daquele estado durante a Revolução de 1930 quando a cidade de Princesa Isabel depois, João Pessoa -, chefiada por José Pereira Lima, declarou-se território livre e resistiu às tropas do governador Álvaro Pereira de Carvalho, incapaz de dominá-la. Inicialmente, o citado refrão foi considerado pela oposição como um insulto à mulher paraibana, criando-se um tumulto quando ela foi cantada em comício de José Américo no mês de maio. Independente dessa reação, uma das "rainhas do rádio", Emilinha, gravou-a com enorme sucesso ainda em 1950. A gravação de Luiz Gonzaga somente viria dois anos depois.

Ainda no mesmo ano de 1952, uma ágil chanchada pegava na onda do sucesso regional para tomá-la como inspiração para a composição da personagem Madame Pau-pereira (Violeta Ferraz), do filme É fogo na roupa. Em uma das primeiras seqüências, o mestre de cerimô- nias do Hotel Quitandinha (Petrópolis, RJ) apresenta publicamente a presidente do $1^{\circ}$ Congresso das Esposas em Defesa da Fidelidade Conjugal e a sua primeira aparição já a caracteriza fortemente: ela surge em cena vestida de paletó e gravata, fumando um charuto e com gestos grosseiros, configurando o estereótipo fácil de homossexual feminina em comédias. Para o que se busca discutir aqui, torna-se difícil precisar o que teria tido mais efeito na generalização da "Paraíba masculina", se a canção de Gonzaga ou se essa chanchada de difícil acesso. A propósito das caracterizações de mulheres na chanchada - e não somente as nortistas ou nordestinas -, Chaia (1980) argumenta que, nesse ciclo de filmes, há uma inversão do "esquema habitual de dominação", sabidamente masculino, pois, aqui, a mulher é a dominadora. Com isso, entende ele, surge um modo interessante de se ridicularizar o mando, a dominação: "Coloca-se no papel de dominador quem menos se espera. $\mathrm{O}$ mando da mulher sobre os outros, nestes filmes, é uma técnica de poder dos subalternos" (p. 69).

\section{O deputado nordestino}

Um outro tipo freqüente em representações satíricas de nordestinos, com relação a traços culturais "naturalizados", é a do tribuno, batizado com freqüência de "deputado nordestino". Provavelmente o mais antigo registro dessa representação que os chanchadeiros entendiam como o "deputado nordestino" esteja em $\mathrm{Na}$ corda bamba (1957), em que um afinador de pianos (Zé Trindade) envolve-se em complicações com bandidos à procura de um valioso colar. Na última meia hora do filme, Zé Trindade alardeia, por vários motivos, que é baiano, o que, entre outras coisas, serve como mote para que seu colega (o palhaço Arrelia) o convide a discursar, sob o argumento de que "baiano gosta de fazer discurso".

Dois anos depois de Na corda bamba, a associação estereotipada de baiano com discursividade gratuita retorna nas chanchada através do citado Mário Tupinambá em um quadro, que tem de engraçado o que tem de deslocado na trama geral da narrativa em que se insere. Tratase do filme Titio não é sopa (RJ, 1959), prota- 
gonizado por Procópio Ferreira. Em determinado momento, Procópio vai à boate que seu afilhado montara com o seu dinheiro sem que ele soubesse. O primeiro dos quadros musicais que lá ocorrem tem uma inusitada introdução: do alto de um coreto, em uma cenografia que remete a uma cidadezinha do interior, com os transeuntesdançarinos fantasiados para uma quadrilha junina, Mário Tupinambá, que não participa da trama do filme, faz a seguinte predileção, bem no tipo que ele criou para a sua identificação no mercado carioca de rádio e TV nos anos $50 \mathrm{e}$ 60: "Na qualidade de baiano ilustre, venho protestar contra esse negócio de carioca se juntar com paulista para dizer que baiano sobe no coqueiro, em dia de chuva, para ver como é que entra água no coco!”.

Voltando às representações de uma exacerbada oralidade como traço específico de nordestinos, em Virou bagunça (RJ), há não apenas um "deputado nordestino", mas um trio, que é convidado a se apresentar em um programa tipo mesa-redonda na TV Olho sobre a seca, sobre a fome no "Norte". Um pouco antes de o programa começar, esses parlamentares são confundidos com os membros do Trio Jerimum (Trio Irakitan) e são postos a esperar. Introduzidos na sala da gerência, os parlamentares são barrados pelo diretor de programação da emissora, e um deles responde, ao que considera uma desfeita, com um curto e acalorado discurso, bem na composição do tipo "deputado nordestino", que celebrizou Mário Tupinambá. Desfeito o equívoco, o trio de parlamentares volta a se encontrar com o diretor de programação da TV, que justifica a necessidade da presença deles em um programa tipo "mesaredonda" porque eles são "nortistas" e, como tal, "conhecem a seca", conhecem o "problema da fome". Temos aqui um clichê, útil certamente a revistas ilustradas e a certos parlamentares: a associação automática de "nortistas" ou nordestinos com fome e seca, temas, por sinal, presentes no rico repertório de Luiz Gonzaga, por exemplo. A argumentação final da personagem interpretada por Paulo Celestino associa representações da seca e da fome com ibope: "É isso que o público quer".

Pelo que se levantou até aqui, pode-se aventar a hipótese de que uma oralidade exacer- bada seria privilégio de nordestinos? Acreditamos que não, mas essa generalização, desprovida de demonstração, tem uma história, digamos, científica. Um das mais antigas associações de uma "nordestinidade" ou, mais precisamente, de uma "baianidade" com um gosto pela retórica gratuita, mais com objeto de adorno do que como um elemento importante em estratégias de argumentação oral, está em um ensaio de Oliveira Lima, publicado originalmente em 1911, intitulado Formação histórica da nacionalidade brasileira. Em seu capítulo "Bahia, centro de luxo, e Minas gerais, centro de atividade", lá se pontifica:

Centro do governo até que o Rio de Janeiro the arrebatasse essa posição [...], a Bahia foi naturalmente o ponto de reunião de um mundo de funcionários, de padres e de magistrados [...]. Foi a cidade por excelência, no Brasil dos oradores sacros, dos poetas didáticos e dos acadêmicos verbosos. Os tonitruantes sermões substituíam o teatro, a ênfase bania a sinceridade, e a retórica dispensava-se do estudo. (Lima, 2000, p. 101-2)

Em maio de 1924, ao resenhar o Manifesto da poesia pau-brasil, de Oswald de Andrade, o historiador paulistano Paulo Prado estende a todo o território nacional o locus de uma exacerbada oralidade: "Esperemos também que a poesia "pau-brasil' extermine de uma vez um dos grandes males da raça - o mal da eloqüência balofa e roçagante" (2004, p. 313).

\section{Por que tantos nordestinos?}

Tomamos como recorte de tempo nesta análise de representações de nordestinos na comédia musical carioca os anos compreendidos entre 1952 e 1961 . Sabe-se que a década brasileira de 1950 se inicia com o registro de uma forte migração em direção à ex-capital federal, São Paulo e Minas Gerais. Fixemo-nos apenas na também ex-Cidade Maravilhosa. Em sua área de influência, passam a residir naquele momento 191.917 mineiros, 55.746 capixabas, 46.990 paulistas, 45.157 pernambucanos, 44.936 baianos, 27.267 alagoanos, 23.209 paraibanos, 18.001 cearenses e 13.468 potiguares, entre outros (Brasil, 1953). Curiosamente, os migrantes naturais de maior expressividade quantitativa no 
período na região da ex-capital federal - provenientes dos vizinhos estados de Minas Gerais, Espírito Santo e São Paulo - não se encontram caracterizados nas chanchadas da época, que, como mostraremos, vão privilegiar a caricatura de nordestinos: pernambucanas (interpretadas pela cearense Nancy Wanderley e pela carioca Sônia Mamede), em maior número, e baianos (interpretados principalmente por Zé Trindade e Mário Tupinambá). Tentemos abordar inicial e brevemente esse descompasso entre estatísticas do IBGE e nordestinos nas telas com base em enfoques diversos: do ponto de vista socioeconômico, do ponto de vista sociocultural, do ponto de vista da sociologia da modernização e do ponto de vista da psicologia social dos estereótipos.

Do ponto de vista socioeconômico, um dado forte é que as grandes secas de 1951, 1953 e 1958 e as conseqüentes levas migratórias dentro do Nordeste e em direção ao então "SulMaravilha" acabaram por colocar problemas de desenvolvimento econômico na ordem do dia, espaço para o florescimento de um discurso sobre a desigualdade no desenvolvimento nordestino. Essa aposta não se desenvolve porque as chanchadas, obviamente, não discutem políticas econômicas. Uma outra dificuldade dessa aproximação entre os migrantes das estatísticas do IBGE e aqueles da chanchada é que os primeiros, aparentemente, teriam sido atraídos pela ex-capital federal pelo seu grande número de estabelecimentos industriais: 4.158. Um número que era três vezes maior do que o apresentado pelo estado do Rio, 1.760 , região de onde provinham mais de 102 mil dos seus migrantes, número inferior apenas ao de mineiros.

Um dado curioso é que, a despeito dessa oferta de empregos na realidade mais imediata, mencionada acima, a chanchada jamais achou alguma graça em narrativas sobre operários ou sobre tramas passadas em oficinas, manufaturas ou fábricas, preferindo auditórios de rádio e TV, palcos de boates, de teatro de revistas e picadeiros. Uma exceção ao que se afirma aqui está em duas participações do ator paraibano Rafael de Carvalho (1918-1981) ainda na chanchada. A primeira como um pedreiro compenetrado, em Titio não é sopa, e a segunda como o encarregado de um alojamento de trabalhadores durante a construção de Brasília, em Um candango na Belacap. Nesse último, a sua participação é breve e se dá logo nas primeiras seqüências, quando intermedia junto à polícia a soltura de colegas que haviam brigado durante um forró no barracão. Ele usa a expressão forrobodó como sinônimo de confusão, e essa é uma das etimologias para forró. Não por acaso, e denunciando uma matriz regional e musical para mais uma estereotipia, há um conjunto de canções valorizando positivamente uma virtual valentia nordestina durante forrós, entre as quais estão "Forró em Limoeiro" (Edgar Ferreira): "Eu que sou do morro, não choro, não corro,/ Não peço socorro quando há chuá/ Gosto de sambar na ponta da faca/ Sou nego de raça e não quero apanhar"; "Cumpadre João" (R. Cavalcanti e J. do Pandeiro): "Cheguei em Caxias num dia de feira/ Me fiz na peixeira e não vi valentão./ No meu Pernambuco, já fui num forró/ Fiz trança, dei nó, lá no ribeirão/ De punhal na mão lá em Limoeiro/ Botei cangaceiro pra baixo do chão", e "Forró de Caruaru" (Zé Dantas): "No forró de Sá Joaninha/ No Caruarú/ Cumpade Mané Bento/ Só fartava tu. [...] Nós dansemo sem pará/ Num galope de matá/ Mas arta madrugada/ Pro mode uma danada/ Qui vei de Tacaratú/ Matemo dois sordado/ Quato cabo e um sargento/ Cumpade Mané Bento/ Só fartava tu".

Do ponto de vista sociocultural, uma outra chave para tamanha visibilidade de nordestinos nas chanchadas talvez pudesse ser buscada em uma forte radiação do rico imaginário que Luiz Gonzaga, por exemplo, trouxe à mídia da época em canções de sucesso, como "Assum preto", "A dança da moda" (1950), "Baião da Penha" (1951), "Paraíba", "Pau-de-arara", "Tudo é baião" e "Xaxado" (todas de 1952), "ABC do sertão", "Vozes da seca" (1953) e "Cabra da peste" (1955). Uma das limitações dessa aposta é que o período de mais ricas caracterizações de nordestinos, coincidindo com filmes de melhor apuro artístico, se dá entre os anos de 1957 e 1960, quando o Rei do Baião já não era mais um recordista de vendas e execução de músicas em todo o país, dado que se registra a rigor para ele entre os anos de 1950 e 1952. 
Mais uma outra possível associação entre representação de migrantes nordestinos e chanchadas talvez pudesse ser produzida com a inclusão de dados da Baixada Fluminense e de sua personagem mais conhecida na época: o alagoano Tenório Cavalcanti. Migrantes nordestinos e do norte de Minas começam a se deslocar para aquela região, após a Segunda Guerra Mundial. Esse período assinala o surgimento de loteamentos clandestinos em áreas antes ocupadas por grandes plantações de laranja, adensando ou originando municípios como Duque de Caxias, Nilópolis e Nova Iguaçu. No começo dos anos 50 , com uma população estimada em mais de trezentas mil pessoas, a Baixada Fluminense é tida como uma das regiões mais pobres do país. Apesar das estatísticas, a Baixada Fluminense somente comparece nas chanchadas em apenas um filme, hoje desaparecido: Carnaval em Caxias (RJ, 1953), em que José Lewgoy interpreta Honório Boamorte, personagem calcada no deputado federal udenista Tenório Cavalcanti, que para lá migrou de Alagoas.

\section{Os donos das vozes}

Ao falarmos de estereotipia, pressupomos obviamente um sujeito para executar esse processo. Em uma obra tão coletiva como um filme de ficção, talvez seja muito difícil precisar o seu principal emissor. Seria este o produtor? Seria o diretor? Seriam os roteristas? Seriam os artistas, preservando assim tipos provenientes do rádio, do teatro de revista ou do circo? Com relação ao primeiro suspeito, o produtor, isso fica também muito difícil de ser afirmado, pois são diversos os produtores do filmes aqui discutidos, se bem que esses poucos diversos se multiplicam em funções diversas na indústria do audiovisual brasileiro. O produtor a bancar mais representações estereotipadas de nordestinos na nossa chanchada, entre os filmes aqui discutidos, é Oswaldo Massaini, um paulistano, também distribuidor (Cinedistri). Ainda neste corpus, quem lhe sucede é o responsável - juntamente com Carlos Manga - pelas nossas melhores chanchadas: Watson Macedo. Há a assinatura desse fluminense, tio de Eliana, seja como produtor, diretor, argumentista, cenógrafo e diretor em seis filmes. A despeito das estereo- tipias, os nordestinos saem-se bem ao final dos seus filmes. Ainda no campo da produção, alternando com algumas poucas direções, está Herbert Richers, que, em nosso corpus, é o produtor de cinco filmes. Na verdade, Richers é o responsável por quase todos os filmes de Zé Trindade de 1958 até 1961, justamente as películas que esse ator baiano protagonizou. Com relação a esses produtores, com pesos diversos na fatura final dos filmes citados, pode-se aventar uma suposição que eles estariam tãosomente investindo naquilo que lhes parecia um retorno mais rápido: fazer filmes que atingissem um grande público, a partir de tipos já consolidados pela então incipiente indústria cultural brasileira.

Se é inquestionável que a representação humorística de nordestinos poderia estar atendendo mercadologicamente àqueles mistos de diretor-produtor-exibidor (Luís Severiano Ribeiro Jr., proprietário da Atlântida nos dois últimos itens do trinômio), talvez isso pudesse ser afirmado também para determinados astros, como Nancy Wanderley ${ }^{4}$ e Zé Trindade, que, filme após filme, repetiam as mesmas caracterizações e, no caso do baiano, às vezes os mesmos bordões machistas. A profusão dessas representações alimentava o mais longo ciclo que o cinema brasileiro já teve, mas é claro que a chanchada, e não somente ela, se beneficiou das leis de proteção ao cinema brasileiro que, desde 1939, reservavam uma parte, mesmo que minúscula, do mercado nacional para o nosso cinema de ficção.

Se é praticamente impossível se saber quem assistia a esses filmes, não é difícil entender que espírito estava por trás de sua produção, além dos já indicados nas funções de produtores, distribuidores e exibidores. Para Chaia (1980), por um lado, havia uma intenção dos produtores de irem "ao encontro dos interesses de um projeto burguês de desenvolvimento" (p. 2); b). Assim, "o discurso veiculado pela chanchada, a nível da totalidade fílmica, esta[ria] em consonância com a ideologia dominante da sociedade

\footnotetext{
4. Pelo que sabemos, a mais antiga caracterização da cearense Nancy Wanderley como pernambucana é em Um americano em Recife, uma paródia do filme Sinfonia de Paris (An American in Paris), em forma de show, montado na boate Monte Carlo, na Praia Vermelha, Rio de Janeiro.
} 
brasileira da época" (p. 39). Por outro lado, ele aponta uma contradição no fato de as situações criadas nos filmes analisados não se colocarem no interior de um processo de produção e, portanto, de existência capitalista. "Os personagens, com raras exceções, ou desconhecem ou não participam das regras ditadas pela forma industrial de produção e pelas normas de convivência urbana" (p. 95). E, mais ainda, as personagens "são seres cujas existências não se enquadram no padrão burguês estabelecido para o desenvolvimento urbano-industrial vigente na sociedade brasileira mesmo nas décadas de 50 e 60 " (p. 96). Por fim, ele afirma: "A chanchada trata dos simplórios que não entram no jogo desenvolvimentista" (p. 97). A forte presença dos "simplórios" leva Chaia a ver nisso uma contradição, pois os filmes seriam o produto de uma burguesia, mas, paradoxalmente, pois em "nível de unidades narrativas mínimas e personagens, o discurso da chanchada reproduz a concepção de mundo do homem simples brasileiro e até coloca criticamente aspectos de sua vivência cotidiana" (p. 39). Essa reprodução, citada acima, se concretizaria na "preocupação com a sobrevivência ou com o cotidiano, recuperação ou ênfase da origem rural, vizinhanças e amizade e contato com valores urbanos" (p. 60). O conceito fundamental para a análise sociológica da chanchada que Chaia destaca é o do "homem simples": "portador de uma concepção de mundo próxima do folclore e do senso comum, que se contrapõe às concepções do mundo oficial" (p. 90). Essa concepção de mundo do simplório é, parcialmente, "embrionária ao grupo social subalterno" e, nela, estão presentes, ainda segundo esse autor, determinados elementos que poderiam ser considerados como relacionados a uma "moral do povo" (p. 90).

\section{Considerações finais}

A despeito das estereotipagens, a recepção do migrante nordestino nas chanchadas, em geral, é positiva, para o que argumenta Dias (1993): "Os migrantes das chanchadas obtinham, diferentemente da maioria das pessoas que migravam, sucesso e reconhecimento na cidade grande" (p. 102). O seu argumento é o seguinte: "Isto não significa que as chanchadas falassem de um Brasil que não existia [...] [mas sim] que a sociedade presente nas chanchadas articulava um mundo oposto ao das classes e elites dominantes desse País na década de 50" (p. 102). No entanto, Chaia já havia ressaltado a especificidade desse "sucesso": "Na chancha$\mathrm{da}$, configura-se quase sempre o trabalho marginal. Ou se é trabalhador marginal ou descaracterizado ou desempregado" (p. 96). Seguindo esses argumentos, talvez pudéssemos apostar, para a construção de uma resposta para essa estereotipação, no fato de que os migrantes nordestinos eram representados majoritariamente como artistas em busca de um estrelato nas rádios e boates cariocas, ou seja, não tínhamos ainda representação deles como competidores no mercado formal de mão-de-obra nãoespecializada, aviltando os salários, como se terá depois, em outros gêneros, no cinema carioca.

Nos filmes elencados, há quase que uma tendência a se tomar como dado que sobreviver em um certo Rio de Janeiro pressupõe o aprendizado de atividade na contravenção. Podemos tomar isso como assimilação? Entendida essa última como um processo que se dá pela "imitação, despercebida e inconsciente, podendo até contrariar a intenção do indivíduo" (Torre, 1976, p. 93). Quando se fala em valores da sociedade recipiente, especialmente nas metrópoles brasileiras, é-se tentado a perguntar se determinados atos de contravenção poderiam ser caracterizados como tal e, se positivo, se eles seriam exclusivos da metrópole.

No corpus trabalhado, talvez haja apenas um caso em que se pode verificar a assimilação de um migrante nordestino através do indicativo do acesso franco a círculos restritos da sociedade maior (Germani, 1974). Trata-se da personagem interpretada por Zé Trindade em Depois, eu conto (RJ, 1956), o diretor-artístico de uma boate, ponto de encontro diário de uma colunista social, burguesas e um frentista de posto de gasolina (Anselmo Duarte), querendo se passar por um "paulista de quatrocentos anos". Esse talvez seja o dado mais próximo de uma assimilação de migrantes nordestinos em chanchadas.

O modo como o migrante desempenha seus papéis é um índice de sua adaptação ou não à sociedade recipiente, adaptação essa que se 
traduz em geral na capacidade do migrantes em desempenhar os papéis sem tensão psicológica excessiva ou intolerável. Com relação à assimilação, as personagens melhor sucedidas nesse aspecto no corpus trabalhado talvez sejam aquelas interpretadas por Zé Trindade. Se a cearense Nancy Wanderley pôde ter marcada sua passagem pelas chanchadas como uma de suas "pernambucanas", Zé Trindade, baiano de Salvador, resolveu fazê-lo pelo que lhe parecia mais natural: ser o baiano oficial desse ciclo em que colaborou como co-argumentista em vários dos títulos que protagonizou, ou seja, ele tinha chances de ter uma maior controle de suas representações. Por isso, dificilmente se tem algum filme que ele não se utilize da autoidentificação para o que acredita ser a localização natural (regional) de uma qualidade dele.

\begin{abstract}
This paper aims to search, to describe and to discuss a presumed Northeastem regional identity in Brazilian fictional cinema (1952-1961), mainly in Carioca musical comedy, also known as chanchada. W e tried to make a brief survey of those representations matrixes and their motivations. With this aim we tried to analize which alltural traits those films have shown as exclusive ones from those people who had born or people had brought up in Brazilian Northeastem; we tried to check and discuss if, in those films, there are data which give us some Northeastem characterization by birth; and we tried to check and disauss if the self-atribution is an important factor when we talk about the process of building of a Northeastem regional identity in brazilian cinema.
\end{abstract}

Key-words: Northeastem; Carioca chanchada; history and criticism; Brazilian cinema; $20^{\text {th }}$ Century.

\section{Referências}

ALBUQUERQUE JR., D. M. Cabra da peste!. Nossa História, Rio de Janeiro, II, 17, mar. 2005. p. 32-35.

ALENCAR, J. O sertanejo. São Paulo: Ática, 1978 [1875].
AMÂNCIO, T. O Brasil dos gringos - Imagens de cinema. Niterói: Intertexto, 2001.

AUGUSTO, S. Este mundo é um pandeiro - A chanchada de Getúlio a JK. São Paulo: Companhia das Letras, 1989.

BRASIL. Anuário estatístico do IBGE. Rio de Janeiro: IBGE, 1953.

CASTRO, R. Carnaval no fogo - Crônica de uma cidade excitante demais. São Paulo: Companhia das Letras, 2003.

CHAIA, M. O tostão furado - Um estudo sobre a chanchada. São Paulo, 1980. Dissertação (Mestado em Sociologia) - FFLCH, USP.

DIAS, R. O. O mundo como chanchada-Cinema e imaginário das classes populares na década de 50 . Rio de Janeiro: Relume Dumará, 1993.

GERMANI, G. Sociologia da modernização Estudos teóricos, metodológicos e aplicados à América Latina. São Paulo: Mestre Jou, 1974.

LIMA, O. Formação histórica da nacionalidade brasileira. São Paulo: Publifolha, 2000.

LIPPMANN, W. Estereótipos. In: ROSENBERG, B.; WHITE, D. (Orgs.) Cultura de massa. São Paulo: Cultrix, 1973. p.149-159.

MORAES, V. Roteiro lírico e sentimental da cidade do Rio de Janeiro. São Paulo: Companhia das Letras, 1992.

NAVARRO, F. Assim falava Lampião. 2. ed. São Paulo: Estação Liberdade, 1998.

PRADO, P. Paulística Etc. São Paulo: Companhia das Letras, 2004 [1925].

TORRE, M. B. O homem e a sociedade - Uma introdução à sociologia. São Paulo: Companhia Editora Nacional, 1976.

VENEZIANO. N. O teatro de revista no Brasil: Dramaturgia e convenções. Campinas, SP: Pontes, 1991.

VIEIRA, J. L. A chanchada e o cinema carioca (19301955). In: RAMOS, F. (Org.) História do cinema brasileiro. São Paulo: Art Ed., 1990. p.129-187. 